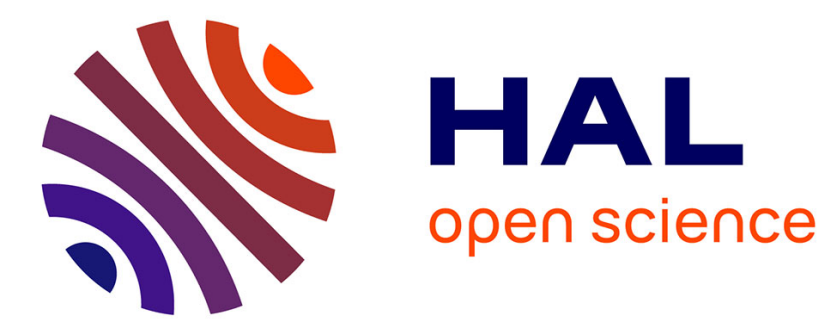

\title{
SUMMARY OF THE CONFERENCE - EXPERIMENTAL ASPECTS
}

\author{
K. Dransfeld
}

\section{To cite this version:}

K. Dransfeld. SUMMARY OF THE CONFERENCE - EXPERIMENTAL ASPECTS. Journal de Physique Colloques, 1984, 45 (C5), pp.C5-529-C5-533. 10.1051/jphyscol:1984579 . jpa-00224200

\section{HAL Id: jpa-00224200 https://hal.science/jpa-00224200}

Submitted on 1 Jan 1984

HAL is a multi-disciplinary open access archive for the deposit and dissemination of scientific research documents, whether they are published or not. The documents may come from teaching and research institutions in France or abroad, or from public or private research centers.
L'archive ouverte pluridisciplinaire HAL, est destinée au dépôt et à la diffusion de documents scientifiques de niveau recherche, publiés ou non, émanant des établissements d'enseignement et de recherche français ou étrangers, des laboratoires publics ou privés. 
JOURNAL DE PHYSIQUE

Colloque C5, supplément au n4, Tome 45, avril 1984

page $\mathrm{C} 5-529$

SUMMARY OF THE CONFERENCE - EXPERIMENTAL ASPECTS

\author{
K. Dransfeld \\ Universitat Konstanz, Fakultat fur Physik, Jacob-Burckhardt-Strasse 35, \\ Postfach 5560, D-7750 Konstanz 1, F.R.G.
}

The dynamics of interfaces is one of the most active research area in solid state physics, the interest arising from fundamental questions as well as from possible applications. The idea to hold a conference on this topic here was conceived by L. Dobrzynski and the program was set up by members of the Oniversities in Lille and at Irvine (Califorsia) in close cooperation.

After the opening ceremony L. Esaki was the first speaker of the conference. He gave an excellent review of the historical development in this field of research which he himself had created by this first proposal (in 1970) to investigate the properties of artificial semiconducting superlattices and quantum wells. As he recalled with amusement the first publications were not accepted by the PHYSICAL REVIEW LEITERS for "being too specialized".

In the next 3 sections I will comment on those topics of the conference which were of special interest to me. Being an "outsider" I apologize before-hand for any incompleteness and I refer the reader for the full details to the proper conference paper in this volume. First, I will discuss the experiments on single surfaces, films and single interfaces. Secondly, superlattices are treated and, finally, some general concluding remarks will be given. The outline of this paper is thus as follows:

I. Single Surfaces, Films and Interfaces

1. Aooustic properties of solid surfaces and films

2. Microscopic structure and diffusion at solid interfaces

3. Dynamics of liquid surfaces and interfaces

4. Surface polaritons

5. Magnetic properties

II. Superlattices

1. How to make them?

2. Acoustic Properties and Raman-Scattering

3. Electronic Properties

4. Optical Experiments

5. Metallic Superlattices

III. Concluding Remarks

1. Surfaces, Films and single Interfaces

I.1. Aooustic Surface waves in the GHz-frequency range can now be observed by optical Brillouin scattering on surfaces of many solids, particularly after the development of the multipass Fabry-Perot spectrometer by J.R. Saderoock (See for exanple papers $1-5)$. They seem to be rather well understood and the same can be said about the elastic waves, like Lamb-, Love- and Stoneley-waves, travelling on solid films and interfaces. They have also been recorded by optical methods $/ 1 /$.

Acoustic Surface waves up to THz-frecuencies, however, have been observed on crystals only recently by the inelastic scattering of electrons or Helium atoms $/ 6,7 /$. 
This is an exciting new field of research of importance also for surface reactions and catalytic processes.

I.2. The stability of interfaces even at elevated temperatures is of great importance for the production of stable periodic superlattices. Therefore it is useful to study the microscopic electronic structure and stability of a foreign atom adsorbed on quantum crystalline surface (see for example papers $/ 8-16 /$ ) in order to be able to predict which interfaces may be particularly stable. Surprisingly, some interfaces are so extremely unstable, that very useful applications can be derived from this instability. This is true, for example, for the c-Lil/ $/ \mathrm{A}_{2} \mathrm{O}_{3}$ interface: the high mobility of $\mathrm{L} i$ ions in this interface is the basis of most solid-state-ionic batteries nowadays in medical use.

I.3. Quite different but also of fundamental interest is the study of capillary waves on liquid surfaces and of waves which propagate on the solid/liquid of liquid/ liquid interface. The observation of these waves by light scattering techniques revealed, for example, that the viscosity of liquids close to surfaces or interfaces is often much higher than the bulk viscosity of the same liquid. The implication of these results for the liquid structure near surfaces is not yet well understood (see papers 5 and 17). As pointed out by Prof. R. Loudon, it might become possible to detect optically the interface waves between two different solutions separated by a biological membrane. Clearly here is an additional motivation for this work.

\begin{abstract}
One might also mention the crystallisation waves on the interface between solid and liquid ${ }^{4} \mathrm{He}$ at low temperatures, which has recently been reported $/ 18 /$.

Due to the lack of latent heat of melting, solidification and melting propagates along the interface as a wave up to frequencies of $1010 \mathrm{~Hz}$ (see also Castaing $/ 19 /$, and Maris $/ 20 /$.
\end{abstract}

I.4. The largest number of papers /21-35/ (together 15) were dedicated to surface polaritons (mostly plasmon polaritons) travelling along metallic/dielectric interfaces. Clearly this is an area of research in rapid expansion. In my view the new experiments with gratings by Zhizhin $/ 36 /$, about which Prof. A. Sievers reported, and the non-linearity at high power levels seemed particularly promising. May be it will also soon be possible to pursue the adsorption of macromolecule on metallic films (out of an aequous solution) by the conversion of light at the point of adsorption from surface polaritons to bulk radiation.

I.5. The magnetic properties of atoms near a surface or interface can be quite different from the behaviour in the bulk (see papers 37-40). For example, the surface may be ferramagnetic while the interior is only paramagnetic. Hebral et al. $/ 41 /$ discovered recently that ${ }_{\mathrm{He}}$ in constricted geometries has a very large excessive specific heat, which may be magnetic in origin. As M. Brodsky /38/ reported, Pd is strongly magnetic if sandwiched between Au-layer, while $\mathrm{Cr}$ between Au-layers becomes superconducting below about 3K. It is not yet clear whether these transformations are caused mainly by mechanical strain in the sandwich (of the order of 18!). By building up alternating magnetic and non-magnetic layers, which are not coupled by exchange forces but only by dipolar fields interesting new magnetic materials can be synthezised $/ 42 \%$.

\title{
II. Semiconducting superlattices
}

II.1. Epitaxial crystal growth techniques now allow the production of very high quality periodic semiconducting superlattices of the type originally proposed by L. Esaki. Samples with many hundred layers of alternating composition and with periodicaliy varying doping can now be built up, each layer being only a few nanometer thick. Especially the molecular beam epitaxy (MBE) is most highly developed. Each layer can be produced smooth on an atomic scale: the large roughness originally generated by the sublimation disappears by subsequent atomic migration, if the conditions are chosen correctly. The most commonly used material is (GaAs/Ga1- $\left.x^{A} x_{x} A s\right)$ which shows good stability and no diffusion, if the Al-content is not too high. 
II.2. As V. Narayanamurti /43/ explained, acoustic waves are reflected from the superlattice planes only if their distance equals a multiple of half an acoustic wavelength. This oould be demonstrated by high frequency acoustic waves generated using superoonducting tunnel junctions as transducers.

It is surprising that "out of resonance" sound propagates across about 100 layers without noticeable loss. By contrast two solids joined or soldered together under atmospheric conditions only have a transmission of about $10 \%$ per interface presumelely due to the presence of absorbing atomic tunnel systems (2 IS) in the interface. These seem to be completely absent in the superlattices mentioned above.

This reflection of acoustic waves of proper wavelenght by the periodic superlattice leads in a natural way to the folding-up of the acoustic branch into the first "minizone" extending from zero to $\pi / d$ (d: superlattice periodicity). Two lectures by M. V. Klein /44/ and by J. Sapriel /45/ gave clear evidence that indeed new Raman-lines appear for superlattices in full accord with a folded aooustic branch. Also the missing of all even orders appears plausible. Not explained yet is a low frequency line (at $13 \mathrm{~cm}^{-1}$ ) and the broad background observed only in superlattices which are rather rich in $\mathrm{A} 1$.

Not very much is knownabout the temperature-dependent acoustic attenuation in superlattices, arising from phonon-phonon or phonon-electron interaction. For phonon propagation parallel to the layer most of the energy will probably be transported - as a guided wave - in the layers of smallest velocity of sound. Phonon focussing well know for anisotropic three dimensional crystals has not yet been investigated for superlattices.

II.3. For the remainder of his talk Narayanamurti /43/ concentrated on the extremely large electronic mobilities (over $10^{6} \mathrm{~cm}^{2} / \mathrm{sec}$ Volt) achieved by Bell Labs in doped superlattices, and furthermore on the special electron-phonon interactions which appear to operate in these structeres. As the consequence the mobility is at very low tenperatures strongly field dependent.

One of the most interesting electronic property of these two-dimensional electronic systems is the quantized Hall-effect, originally discovered by von Klitzing, Dorda and Pepper $/ 47 /$. But this area of research has just been discussed a few weeks earlier at another conference and has therefore not been treated at lille in detail. But one theoretical paper /48/ has been presented.

II.4. Last not least two invited lectures (papers 49-50) were given on the optical properties of semiconducting superlattices. It is the optical behaviour of quanitum wells and superlattices which is most closely related to various application of these structures. Pinczuk /49/ gave a review on the resonant light-scattering by electrons in heterostructures including intersubband transitions, transverse plasma oscillations and transitions between Landau-levels in the presence of magnetic field. M. Voos /50/ first described the optical absorption and luminescence in GaAs/GaAlAs superlattices and then presented new interesting results on InAs/GaSb structures: depending on the layer thickness, the superlattice becomes either semiconducting (for $\mathrm{d}<100 \AA$ ) or semimetallic (for $\mathrm{d}>100 \mathrm{~A}$ ).

II.5. C.M. Falco/51/ gave an interesting review on metallic superlattices produced by sputtering alternate layers of two metals which do not ordinarily mix, for example $\mathrm{Nb} / \mathrm{Cu}$ or $\mathrm{Mo} / \mathrm{Ni}$. The elastic constant (particularly the shear elastic constant) shows a surprising anomalous softening $($ by $\sim 30 \%)$ when the thickness of the alternate film is $25 \mathrm{~A}$ : At this critical film thickness there is apparently a competition between different local order , no definite crystal structure exists and the system fluctuates between different principles of local order reminiscent to the liquid state $/ 51 /$.

\section{Concluding remarks}

The conference gave a rather complete and up-to-date report on most new developments concerning the dynamics of interfaces. 
Perhaps it would have been interesting to leam more about, for example, the quantum Hall-effect and about applications of quantum wells and superlattices. But something has to be left over for the next time. Very recently progress has also been made on phonon-emission from Josephson-junctions and on the dynamics of electrically charged He-films, to mention two more rather special examples.

In view of the rather expensive MBE equipment which is the prerequisite for participating in many of the experiments, it seems desirable to increase the cooperation between neighboring institutions. I have the impression that the conference has also served a good purpose in bringing together owners and prospective users of the existing MBE set-ups.

I am grateful to the lecturers and to the participants for several illuminating discussions and last not least to the organizers for inviting me to such an exciting conference.

REFERENCES

1. SANDERODCK J.R.

2. BORTOLANI $\mathrm{V}$.

3. TILIEY D.R., ALBUQUUERQUE E.L. and OLIVEROS M.C.

4. NIZZOLI F., FRANCHINI A, and SANTORO G.

5. LOUDON R.

6. SZEFTELL J., IEEHWALD S. and IBACH H!

7. COIDAMMER W. and LUDWIG $W$.

8. HERMAN $\mathrm{F}$.

9. FREEMAN A.J., XU I., OHNISHI S. and JARLIBORG T.

10. QUARESIMA, PATETIA F., SETTE F., CAPASSO C., SAVOIA A., PERFEITI P. and MARGARTIONDO G

11. FLORES F., SANCHEZ-DEHESA I, and GUINEA F.

12. KAHN A., BONAPACE C.C. and LI K.

13. BOLMONT D., CHEN P. and SEBENNE C.A.

14. IEI.AY G. and MEIOIS J.J.

15. KUMAR V. and BENNEMANN K.H.

16. BORENSZTEIN Y., LOPEZ-RIOS T. and VUYE G.

17. VISSER D., VAN HIJNINGEN N.C.J.A. and DIL J.G.

18. PARSHIN A.Y., 4th Int. Conf. on Phonon Scatt. in Solide, Stuttgart 1983

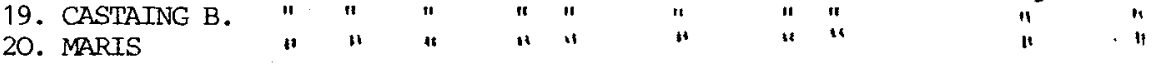

21. ABELES F.

22. SIEVERS A.J., SCHLESINGER $\mathrm{z}$. and CHABAL V.J.

23. USHIODA S.

24. MARIIN B:G. and WAIIIS R.F.

25. GIULANI G.F., QUINN I.I. and WALLIS R.F.

26. STEGEMAN G.

27. KOTETES E.S., CHEN Y.I., SONEK G.I. and BALIANTYNE J.M.

28. BOARDMAN A.D. and EGAN P.

29. CHEN Y.I. and CARTER G.M.

3O. BOARDMAN A.D., COOPER G.C. and EGAN P.

31. BOARDMAN A.D. and EGAN P.

32. USHIODA S. and PIERCE R.M.

33. ZIERAU W., MARADUDIN A.A. and FALTER C.

34. DAWSON P. and WALMSLEY D.G.

35. FORSTMANN $F$. and KEMPA K.

36. ZHIZHIN G.N., MOSKALOVA M.A., SIGAREV A.A. and YAKOVLEV V .A. , Optics Commun. 43 (1982) 31

37. BEAL-MONOD M.T.

38. BRODSKY M.

39. SHINJO T., HOSOITO N., KANAGUCHI K., TAKADA T. and ENDOH Y.

40. WALKER J.C., DROSTE R., STERN G. and TYSON J.

41. HEBRAL B., PUECH L. and THOULOUZE D. I. de Physique 43,809(1982)

42. CAMLEY R.E.

43. NARAYANAMURTI $V$.

44. KL,EIN M.V.

45. SAPRIEL J., MICHEL I.C., TOLEDANO J.C. and VACHER R.

46. JUSSERAND B., PAQUET D., RECRENY A, and KERVAREC $J$. 
47. VON KLITZING K., DORDA G. and PEPPER M., Phys. Rev. Lett. 45,494(1980)

48. YING S.C. and DA CUNHA LIMA I.C.

49. PINCZUK A.

50. VOOS M.

51. FALCO C.M. 